\section{Mining the seams of our Solar System}

\author{
Joseph A. Burns
}

Resources of Near-Earth Space. Edited by J. Lewis, M. S. Matthews and M. L. Guerrieri. University of Arizona Press: 1993. Pp. $977 . \$ 85$

IN the decade before 1492, when Columbus was shuttling across the Iberian peninsula seeking royal sponsors for his so-called "Enterprise of the Indies", the Genoan sea captain read three books over and over again. These volumes were presumably called upon by Columbus in discussion with various sovereigns to buttress his claim that Asia, with its kingdoms of astonishing riches, lay only slightly west of Europe. The best known work was Marco Polo's Travels which incorrectly reported a vast eastward extent to China and the presence of a fabuluously rich Japan supposedly some $2,500 \mathrm{~km}$ further east off the Chinese coast. Another was a world geography written 75 years earlier by a French theologian-astrologer who conveniently maintained that the Western Ocean was quite narrow. A third was a compendium of enticing facts about China

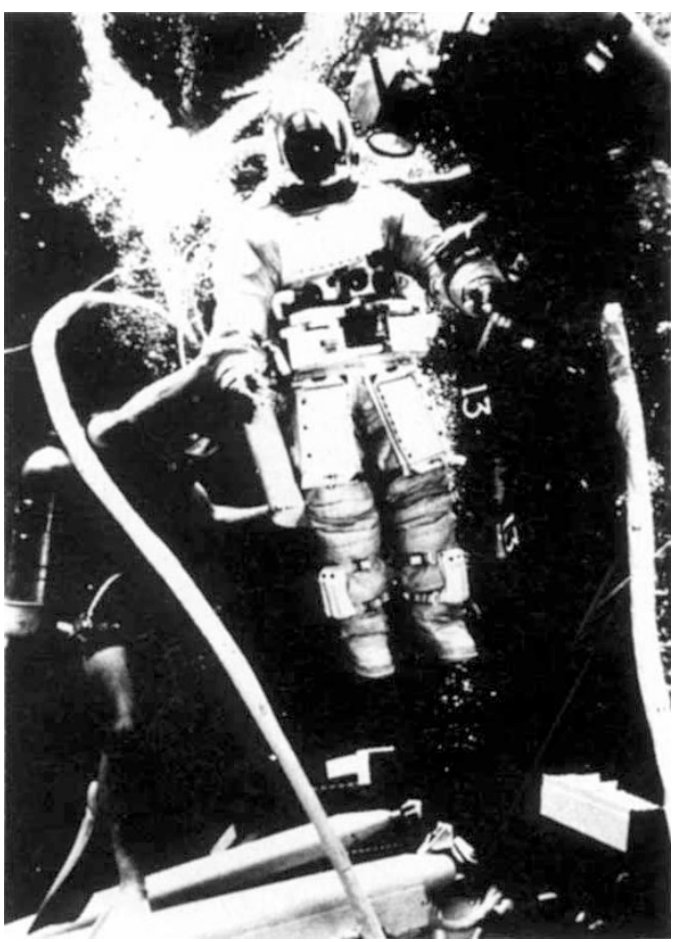

BUBBLE chamber - a Skylab astronaut, assisted by scuba divers, in a "Neutral Buoyancy Simulator" test. Taken from History of Rocketry and Astronautics, AAS History Series, Vol. 11, symposia edited by Roger D. Launius. Published by American Astronautical Society, $\$ 60$ (hbk); $\$ 40$ (pbk). prepared in 1477 by Pope Pius II; here the East was portrayed as a land of great wealth inhabited by bizarre beasts and peculiar peoples. Of course, today we know that the information in these ancient books, although among the most accurate of its day, was flawed. Nonetheless, the volumes made intriguing reading and they accomplished Columbus's purpose.

Resources of Near-Earth Space may play a role similar to Columbus's travelling library for the possible future exploration of Earth's celestial neighbours - the Moon, nearby asteroids, Mars and its two tiny satellites. This book contains brief, up-to-date descriptions of the target bodies and discusses how the materials on them might be exploited. Although one might expect space-age hucksterism on such a topic, the book does relatively little marketing. Only the introductory chapter, written by one of the editors, John Lewis, and two other space scientists, extols the economic potential of nonterrestrial resources, stating that these objects are "rich in materials of great potential value to humanity" that "in the long term . . . may be of great importance here on Earth". But even this chapter ends with a note of caution: although "we cannot yet answer [whether such ventures are economically viable] . . . it would be irresponsible not to seek the answers dilligently".

About a third of the book's 30 or so chapters concern the physical and chemical properties of Earth's nearest neighbours, as understood largely from telescopic observations. These articles, written by established planetary scientists of excellent reputation, focus especially on various aspects of Apollo/Amor asteroids and Mars; by contrast, only single chapters are devoted to the Moon, short-period comets and the Martian satellites. In most cases, after reviewing current knowledge, the authors of these 'science' chapters attempt to interpret the known characteristics in terms of potential resources.

Much of the rest of the book, prepared by a refreshing combination of engineers, industrial technologists and space scientists, describes how these resources might be mined, extracted and processed in the hostile, low-gravity environment of space. For example, there are six chapters concerning the production of oxygen on the Moon, and additional ones about the processing of lunar basalts as well as refractory and non-volatile materials. Several other studies describe possible volatile sources on the Moon, carbonaceous asteroids and Mars. And there are even discussions of how Martian resources might be called upon to provide life support and fuels for return voyages. These presentations are a mixed bag: some provocative, others trivial extensions of mundane terrestrial technology.

Only a few chapters present mission profiles, or address the logistics of transporting machines and necessary supplies to process the extraterrestrial materials and then to return the finished products to market on Earth. Even less time is spent analysing the pivotal question of whether today's (or tomorrow's) launch costs could make the exploitation of space profitable sometime in the foreseeable future.

Broadening its purview, the book ends with J. Pollack and C. Sagan's fairly general questioning of whether Mars or Venus could be made habitable through some grand work of planetary engineering; these authors conclude that the task is too great and, in any case, is questionable on ethical grounds. Instead they argue that humans, before attempting to improve the habitability of other worlds, should first safeguard Earth by countering global warming through a programme of extensive reforestation.

Resources of Near-Earth Space is principally valuable because it provides the first opportunity for practising space scientists to appreciate what knowledge futurists will need, while informing aerospace engineers of just how limited our current knowledge is about even Earth's nearest neighbours. The editors intend the volume to guide industrial and governmental project managers who are starting to consider the feasibility of using nonterrestrial materials. This volume certainly will not be the last word on the topic but it should generate considerable discussion among thoughtful futurists. Will the book be carried by contemporary Columbuses as they go to request government support for their exploitation of some far-off land? I wonder.

Joseph A. Burns is in the Departments of Astronomy and of Theoretical and Applied Mechanics, Cornell University, Ithaca, New York 14853, USA.

- Also recently published is Preservation of Near-Earth Space for Future Generations, edited by John A. Simpson. The book, which is based on a symposium held to mark the hundreth anniversary of the University of Chicago in June 1992, covers the technical aspects and the economic, legal and international issues surrounding the future uses of space. Cambridge University Press, £50, $\$ 79.95$ 